\title{
An Alternative Technique of Intraoperative Identification of Multiple Muscular Ventricular Septal Defects
}

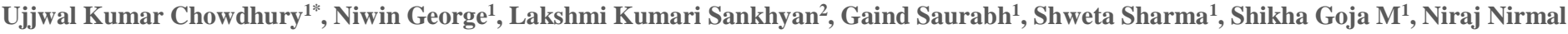 \\ Pandey $^{1}$ \\ ${ }^{1}$ Cardiothoracic Centre, All India Institute of Medical Sciences, New Delhi-110001 22Department of Cardiothoracic and Vascular Surgery, All India \\ Institute of Medical Sciences, Bilaspur, Himachal Pradesh
}

*Corresponding Author: Ujjwal Kumar Chowdhury, Professor Department of Cardiothoracic and Vascular Surgery AIIMS, New Delhi 110029, INDIA

Received Date: September 10, 2021; Accepted Date: October 11, 2021; Published Date: October 26, 2021

Citation: Ujjwal Kumar Chowdhury, Niwin George, Lakshmi Kumari Sankhyan, Gaind Saurabh, Shweta Sharma1, Shikha Goja M, Niraj Nirmal Pandey. (2021) An Alternative Technique of Intraoperative Identification of Multiple Muscular Ventricular Septal Defects. J. Clinical Cardiology and Cardiovascular Interventions, 4(17); Doi:10.31579/2641-0419/222

Copyright: (C) 2021 Ujjwal Kumar Chowdhury, This is an open-access article distributed under the terms of the Creative Commons Attribution License, which permits unrestricted use, distribution, and reproduction in any medium, provided the original author and source are credited.

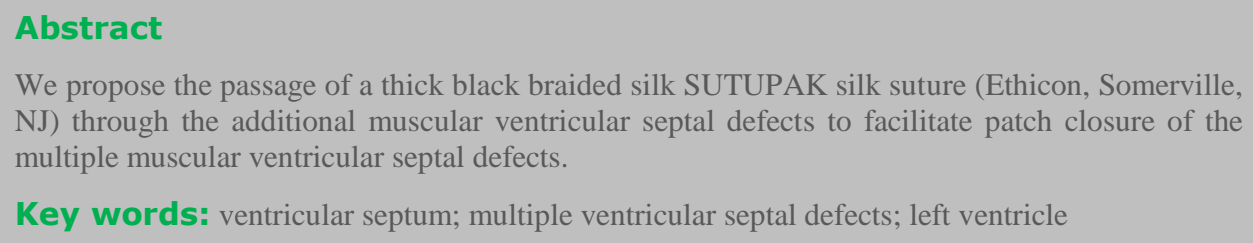

\section{Introduction}

Despite advancements in surgical and interventional techniques, closure of multiple muscular ventricular septal defects (VSDs) is associated with significant perioperative mortality, residual VSDs, ventricular dysfunction, and complete heart block. [1-4]

An analysis of operations in the STS Congenital Heart Surgery Database during the 4-year time period of 2005 through 2008 inclusive, revealed the following four findings:

1. Multiple VSDs take longer to close.

2. When compared with the more common perimembranous VSD, the rate of heart block is three times higher with muscular VSDs and multiple VSDs.

3. When compared with the more common perimembranous VSD, the rate of unplanned reoperation is over four times higher with muscular VSDs, and almost twice as high with multiple VSDs.

4. When compared with the more common perimembranous VSD, the rate of mortality before discharge from the hospital is over twice as high with muscular VSDs and over three times as high (8.5\%) with multiple VSDs. [1]
These complications primarily results from difficulties associated with inadequate exposure and closure. We report the technique and results in 5 patients with multiple muscular VSDs with severe pulmonary arterial hypertension (PAH) using a No. 3 SUTUPAK silk suture through a transtricuspid approach.

\section{Clinical Summary}

Between January 2019 and May 2021, 5 patients underwent patch closure of multiple muscular VSDs by a single surgeon (corresponding author) using the surgical technique described after informed written consent from their parents / guardians.

Their ages at the time of operation were 2, 3, 4, 3 and 3 months respectively. Their weights were $3.2,3.6,4.0,3.6$, and $3.4 \mathrm{~kg}$ respectively. Two-dimensional color Doppler echocardiography demonstrated multiple VSDs with evidence of severe PAH. Intraoperatively, pulmonary arterial pressure (systolic/diastolic) ranged between 98/32 to $110 / 36$ $\mathrm{mmHg}$.

\section{Operative Technique}

We used a transtricuspid approach to close the multiple muscular VSDs in these patients. On moderately hypothermic CPB, the heart was arrested using St. Thomas based cold blood cardioplegia (Figures 1A-1F). 

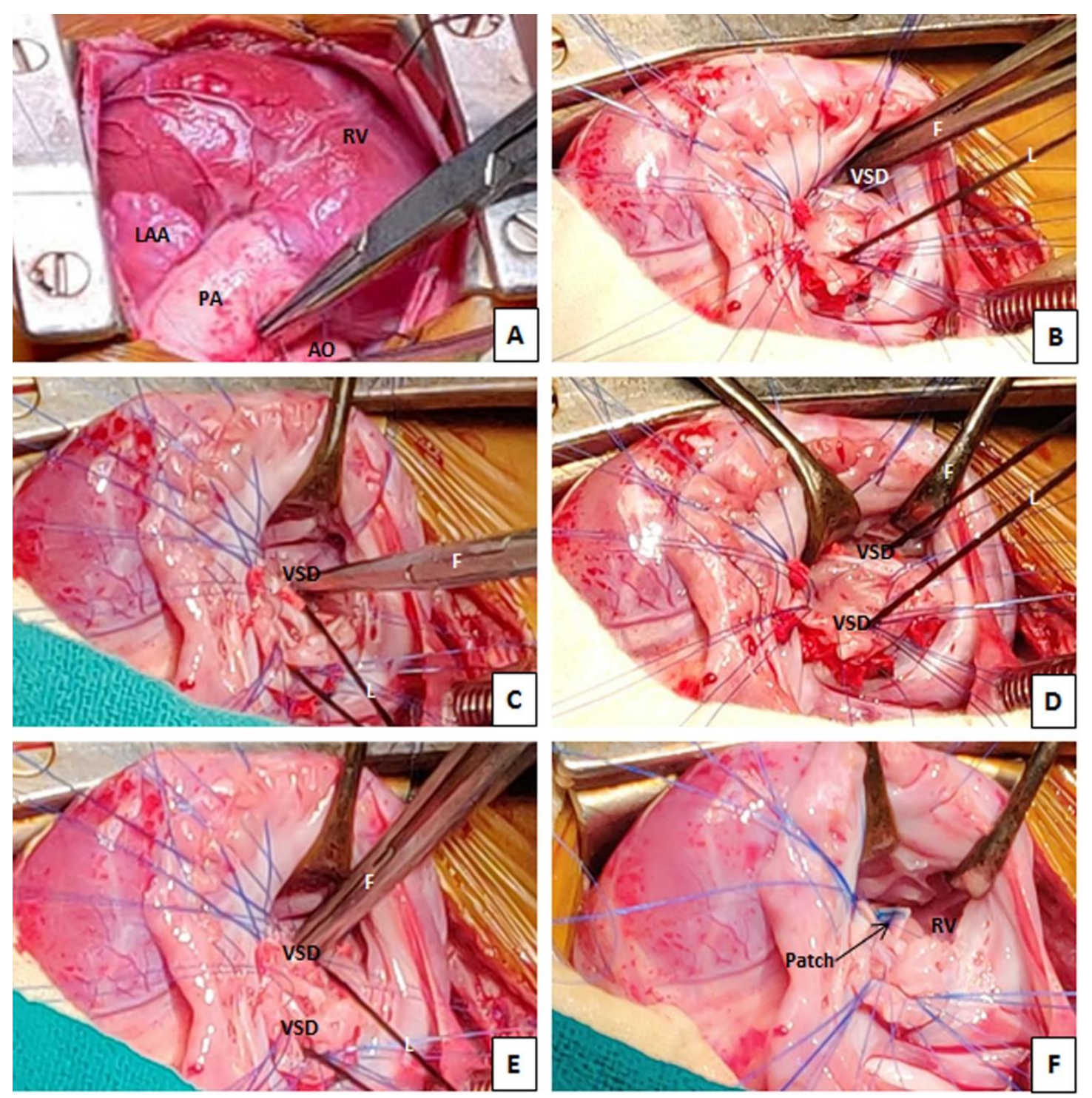

Figures 1A-1F: Surgical photograph of passage of a thick, black braided silk ligature (L) through the additional muscular ventricular septal defect (VSD).

1A- shows the small aorta (AO), distended right ventricle (RV), and tense hypertensive pulmonary artery (PA).

1B, 1C- the tip of the silk ligature is looped through the additional VSD using a right angle forcep (F). Traction on the silk loop facilitated exposure of the margins of the additional VSD.

1D, 1E- two ventricular septal defects were closed separately using Dacron polyester patches and 5-0 interrupted pledgeted polypropylene sutures.

$1 \mathrm{~F}$ - shows the repaired additional ventricular septal defect.

A right atriotomy was fashioned and a left ventricular vent (Medtronic DLP, Medtronic, Minneapolis, Minn) was inserted through the patent foramen ovale or a surgically created atrial septostomy. The larger VSD could be easily located via the tricuspid valve. A blunt tip right angled forceps was negotiated through the suspected location of the muscular VSD's gently without the use of any force except for the weight of the angled clamp. A DeBakey forcep was held in the left ventricle through larger inlet muscular VSD or through the atrioseptostomy. The metallic sound of the two metal tips touching each other indicated that the right angled clamp has negotiated the muscular defect.
Since the additional muscular VSD was apically located and was covered with muscular trabeculae, a No.3 SUTUPAK silk suture (Ivory Braided silk, SW 218, Johnson and Johnson Inc, Somerville, NJ) was looped through the apical VSD to facilitate exposure. Precautions were taken to ensure placement of the tip of the blunt right angled forceps to the margins of the VSD while grasping the silk under vision to avoid inadvertent injury to the mitral valve.

Gentle traction of the silk loop in different directions allowed complete closure of the VSDs without division of the moderator band or right ventricular trabeculae and avoided a left ventriculotomy. 
Both VSD's were closed individually using a knitted Dacron polyester patch Bard ${ }^{\circledR}$ Savage ${ }^{\circledR}$ filamentous knitted polyester fabric, Bard Peripheral Vascular Inc., Tempe, AZ, USA), and multiple interrupted 40 polypropylene pledgeted mattress sutures. Pledgeted sutures were strategically placed circumferentially in order to secure the patch and prevent diminution of the right ventricular cavity or inflow occlusion across the inlet septum.

The tricuspid valve was checked for functional competence by insufflation of saline into the right ventricle. This maneuver is also useful for verifying obliteration of any residual defect, by observing the amount of saline returning from the left ventricular vent. The atrial septal defect was closed.

Pacing wires were placed and tested regardless of the rhythm. Patients were weaned off $\mathrm{CPB}$ in the usual manner. After placement of two patches, transient period of septal akinesis or dyskinesis was common. Following intraoperative transesophageal echocardiography, blood samples were taken from the SVC and the pulmonary artery for oxymetry. It did not reveal any step-up of oxygen saturation in the pulmonary artery. Postoperative management included the use of inodilators and pulmonary vasodilators. Postoperative echocardiography revealed normalization of pulmonary arterial pressure, intact atrial and ventricular septa without any residual shunting.

There were no early or late deaths on follow-up visit ranging from 18-20 months. Doppler echocardiography revealed normal biventricular function and absence of any residual VSDs with systemic arterial oxygen saturation ranging from $96 \%-99 \%$.

\section{Discussion}

Optimal management of multiple muscular VSDs remain controversial. Myriad of surgical techniques have been described, including initial pulmonary artery banding, use of an "oversized pericardial patch" into the left or right ventricle after dividing the moderator band, and septomarginal trabeculae, use of a composite patch of pericardium and Dacron with or without transfixation sutures in the middle of the patch, use of biologic glue, the felt sandwich technique, transatrial reendocardialization technique, septal obliteration technique, two-patch, and right ventricular apex exclusion technique, and a hybrid strategy with perventricular device closure. [3-14]

Although different groups have achieved successful results with individual strategies, each technique is associated with important limitations, and long-term results of most of these techniques are not available.

The moderator band and multiple trabeculations beneath trabecular VSD create a multiperforated wall that hides the trabecular VSD, especially those located at the apex. The key to closure of multiple VSDs is accurate identification, edge detection, and proper cavitary entry. The presence of numerous muscular trabeculations on the right-side of the ventricular septum creates uncertainties in defining the true edges of the VSD. Division of the moderator band and trabeculae have been performed to clearly define the margins of the VSDs. [4,6,7]

Although the use of an apical left ventriculotomy to improve exposure of VSD has facilitated more accurate repair, without late adverse sequelae in many series, several investigators have reported late apical aneurysm formation, ventricular arrhythmia, left ventricular dysfunction, and cardiac transplantation. [1,9-11,14]

In an effort to improve exposure of the margins of VSD without transecting the trabeculae or the moderator band, we railroaded the ductus silk suture through the apical VSD which facilitated placement of deep pledgeted sutures around margins of the VSD.

It is true that this technique only works if each secondary VSD has been definitely identified by passage of the right angle forceps. However, in cases of true "Swiss-cheese VSDs", it remains difficult to ascertain the true margins of all defects located within the right ventricular apex through the transtricuspid route, and this technique is indeed useful in cases of isolated multiple VSDs. An alternative approach of oversized patch technique, septal obliteration/exclusion technique or cardiac transplantation may be chosen in cases of severe forms of "Swiss-cheese VSDs". [1,3,4,6,7]

\section{Conclusions}

Looping and traction of a thick silk suture around the additional muscular VSDs may allow optimal visualization of the margins of VSD to facilitate placement of sutures without having to resort to division of the trabeculae or septal band, thereby avoiding residual defects.

We submit this technique as a useful addendum in the armamentarium of congenital heart surgeons dealing with multiple ventricular septal defects.

\section{Author's contribution}

\begin{tabular}{|l|c|c|c|c|c|c|c|c|}
\hline $\begin{array}{l}\text { Author's } \\
\text { name }\end{array}$ & $\begin{array}{c}\text { Concept/ } \\
\text { design }\end{array}$ & $\begin{array}{c}\text { Data analysis/ } \\
\text { interpretation }\end{array}$ & $\begin{array}{c}\text { Drafting } \\
\text { article }\end{array}$ & $\begin{array}{c}\text { Critical } \\
\text { revision }\end{array}$ & $\begin{array}{c}\text { Approval } \\
\text { of article }\end{array}$ & Statistics & Funding & $\begin{array}{c}\text { Data } \\
\text { Collection }\end{array}$ \\
\hline $\begin{array}{l}\text { Ujjwal } \\
\text { Kumar } \\
\text { Chowdhury }\end{array}$ & $\square$ & $\square$ & $\square$ & $\square$ & $\square$ & - & - & $\square$ \\
\hline $\begin{array}{l}\text { Niwin } \\
\text { George }\end{array}$ & $\square$ & $\square$ & $\square$ & $\square$ & $\square$ & - & - & $\square$ \\
\hline $\begin{array}{l}\text { Lakshmi } \\
\text { Kumari } \\
\text { Sankhyan }\end{array}$ & $\square$ & $\square$ & $\square$ & $\square$ & $\square$ & - & - & $\square$ \\
\hline $\begin{array}{l}\text { Gaind } \\
\text { Saurabh }\end{array}$ & $\square$ & $\square$ & $\square$ & $\square$ & $\square$ & - & - & $\square$ \\
\hline $\begin{array}{l}\text { Shweta } \\
\text { Sharma }\end{array}$ & $\square$ & $\square$ & $\square$ & $\square$ & $\square$ & - & - & $\square$ \\
\hline Shikha Goja & $\square$ & $\square$ & $\square$ & $\square$ & $\square$ & $\square$ & - & - \\
\hline
\end{tabular}


Statement of human rights/ethical approval: The authors assert that all procedures contributing to this study comply with the ethical standards of the relevant national guidelines on human experimentation and with the Helsinki declaration of 1975, as revised in 2008 .

Conflict of interest: No potential conflicts exist

Source of funding: No funding was provided

Availability of Data: Data available in article supplementary material

\section{References}

1. Morales DL, Khan MS, Turek JW, et al. Report of the 2015 Society of Thoracic Surgeons Congenital Heart Surgery Practice Survey. Ann Thorac Surg. 2017; 103(2): 622-628.

2. Lopez L, Houyel L, Colan SD, Anderson RH, Beland MJ, Aiello VD, et al. Classification of ventricular septal defects for the eleventh iteration of the international classification of diseases- Striving for consensus: A report from the International Society for Nomenclature of Paediatric and Congenital Heart Disease. Ann Thorac Surg 2018; 106: 1578.1589 .

3. Jacobs ML, Jacobs JP. Operative techniques for repair of muscular ventricular septal defects. Op Tech Thorac Cardiovasc Surg 2010,

4. Kitagawa, T, Kitaichi, T, Sugano M, et al. Techniques and results in the management of multiple ventricular septal defects. Gen Thorac Cardiovasc Surg 2013; 61, 367-375.

5. Corno AF, Ladusans EJ, Pozzi M, Kerr S. FloWatch ${ }^{\circledR}$ versus conventional pulmonary artery banding. J Thorac Cardiovasc Surg 2007; 134: 1413-1419.
6. Black MD, Shukla V, Rao V, et al. Repair of isolated multiple muscular ventricular septal defects: the septal obliteration technique. Ann Thorac Surg. 2000; 70(1): 106-110.

7. Mace L, Dervanian P, Le Bret E, et al: 'Swiss-cheese' septal defects: Surgical closure using a single patch with intermediate fixings. Ann Thorac Surg 1999; 67(6): 1754-1758.

8. Alsoufi B, Karamlou T, Osaki M, et al. Surgical repair of multiple muscular ventricular septal defects: the role of reendocardialization strategy. J Thorac Cardiovasc Surg. 2006; 132: 1072-1080.

9. Tsang VT, Hsia TY, Yates RWM, et al. Surgical repair of supposedly multiple defects within the apical part of the muscular ventricular septum. Ann Thorac Surg 2002; 73: 5863.

10. Hanna B, Colan SD, Bridges ND, et al: Clinical and myocardial status after left ventriculotomy for ventricular septal defect closure. J Am Coll Cardiol 1991; 17: 110A.

11. Asou T. Surgical management of muscular trabecular ventricular septal defects. Gen Thorac Cardiovasc Surg 2011; 59: 723-729.

12. Holzer R, Balzer D, Cao QL, et al. Amplatzer muscular ventricular septal defect investigators. Device closure of muscular ventricular septal defects using the amplatzer muscular ventricular septal defect occluder: immediate and mid-term results of a US registry. J Am Coll Cardiol 2004; 43: 1257-1263.

13. Feltes TF, Bacha E, Beekman RH, et al. Indications for cardiac catheterization and intervention in pediatric cardiac disease. A scientific statement from the American Heart Association. Circulation 2011; 123; 2607-2652.

14. Shin HJ, Jhang WK, Park JJ, et al. Left ventricular function after left ventriculotomy for surgical treatment of multiple muscular ventricular septal defects. Ann Thorac Surg 2011; 92: 1490-1493.
This work is licensed under Creative Commons Attribution 4.0 License
Ready to submit your research? Choose Auctores and benefit from:

* fast, convenient online submission
rigorous peer review by experienced research in your field
rapid publication on acceptance
* authors retain copyrights
* imique DOI for all articles
immediate, unrestricted online access

At Auctores, research is always in progress.

Learn more www.auctoresonline.org/journals/clinical-cardiology-andcardiovascular-interventions 